\title{
ORGANIZACIÓN Y EXPLOTACIÓN DE LOS PUERTOS ITALIANOS: SITUACIÓN ACTUAL Y PROPUESTA DE REFORMA
}

\author{
BARTOMEU TRIAS PRATS \\ Universitat de les Illes Balears \\ tomeu.trias@uib.es
}

\begin{abstract}
Cómo citar/Citation
Trias Prats, B. (2017).

Organización y explotación de los puertos italianos: situación actual y propuesta de reforma. Revista de Administración Pública, 202, 437-469. doi: https://doi.org/10.18042/cepc/rap.202.15
\end{abstract}

\section{Resumen}

Hace ya más de veinte años, antes incluso de que en el ámbito de la Unión Europea aparecieran los primeros intentos serios de extender el proceso liberalizador al ámbito de los servicios portuarios, la Ley 84/1994 diseñó un nuevo sistema de administración de los grandes puertos italianos que respondía precisamente a ese objetivo: atribuir a las llamadas Autoridades Portuarias la función pública de regulación de la explotación portuaria, y dejar en manos de la iniciativa privada el desarrollo de las actividades económicas de prestación de las operaciones y servicios portuarios. Todo ello con la finalidad última de mejorar la competitividad del sistema portuario. Sin embargo, la realidad de la Ley puso en evidencia que su contenido no estaba del todo en concordancia con su objetivo. Y la experiencia del tiempo transcurrido, por otra parte, ha demostrado que la competitividad de los puertos italianos sigue todavía lastrada por algunas deficiencias que la Ley no ha sabido resolver. En este escenario, desde hace algunos años está en trámite una propuesta de reforma de la legislación portuaria. Se trata, no obstante, de un proyecto aún inacabado. Y lo que es tal vez más

1 Profesor contratado doctor de Derecho Administrativo. 
preocupante, se trata de una propuesta de reforma que plantea dudas sobre si sabrá dar adecuada respuesta a los problemas que trata de abordar.

\title{
Palabras clave
}

Puertos; Autoridades Portuarias; servicios portuarios; liberalización.

\begin{abstract}
Already more than twenty years ago, before even risking the first serious attempts at the level of the European Union extend the liberalizing process within the scope of the port services Act 84/1994 design a new system of administration of the large Italian ports that respond precisely to that goal: attributed to port authorities the public function of regulation of port operating, and allow the development of economic activities for the provision of port services and operations in the hands of private initiative. And all with the ultimate aim of improving the competitiveness of the port system. However, the reality of the law has shown that its content was not fully in accordance with its objective. And the experience of time, on the other hand, proved that the competitiveness of Italian ports is still ballasted by some shortcomings that the law has failed to resolve. In this scenario, some years is pending a proposed reform of port legislation. It is, however, a still-unfinished project. And what is perhaps most worrying, is a reform proposal that raises questions if you know give adequate response to the problems that tries to address.
\end{abstract}

\section{Keywords}

Ports; port authorities; port services; liberalization. 


\section{SUMARIO}

I. INTRODUCCIÓN: 1. El modelo portuario anterior a la ley de 1994. 2. La necesaria reorganización de las actividades empresariales desarrolladas en el puerto. II. LA LEY DE 28 DE ENERO DE 1994: 1. La Administración portuaria: Autoridades Portuarias y autoridades marítimas. 2. Administración pública y explotación privada. El mercado de los servicios y las operaciones portuarias. 3. La discutida naturaleza de las autoridades portuarias: sus actividades económicas. III. LA PROPUESTA DE REFORMA DE LA LEGISLACIÓN PORTUARIA: 1. Deficiencias y retos del sistema portuario. 2. El proyecto de modificación de la Ley 84/1994.

\section{INTRODUCCIÓN}

\section{EL MODELO PORTUARIO ANTERIOR A LA LEY DE 1994}

La regulación actual del sistema portuario italiano tiene su origen y principal referente en la Ley 84/1994, de 28 de enero, que entre otros aspectos destacados instituye la figura de las "Autoridades Portuarias» ${ }^{2}$.

Antes de esta norma, el Código de la Navegación (Real Decreto 347/1942, de 30 de marzo) había tratado de convertir a las llamadas «autoridades marítimas», concebidas como dependencias periféricas del Estado central, en la figura clave de los puertos ${ }^{3}$, atribuyéndoles una amplia variedad

2 M. Calabró (2013), «El sistema portuario en Italia. Aspectos críticos y posible desarrollo", Revista Xuridica da Universidade de Santiago de Compostela, 22, 2, págs. 1-11.

3 Las «autoridades marítimas» quedaban integradas en la Capitanía del Puerto, cuya aparición se remonta al Real Decreto 243/1865, de 20 de julio. Dependiente del Ministerio de Marina, y con atribuciones relativas tanto a la navegación mercantil como a la militar, la Capitanía nacía con el objetivo de convertirse en el instrumento a través del cual el poder central de una Italia recientemente unificada pudiera controlar la administración periférica del litoral. Sobre el origen histórico y la evolución de la Capitanía puede verse A. Xerri Salamone (1998), L'ordinamento giuridico dei porti italiani, Milán: Giuffrè. 
de funciones que abarcaban la coordinación, control y gestión administrativa de la actividad portuaria ${ }^{4}$.

No obstante, antes incluso que eso, ya desde principios del siglo anterior en los principales puertos empezaron a constituirse, bajo fórmulas muy diversas, entes públicos especiales cuyo objetivo específico era el de asumir la tarea de administración de todas las actividades que se desarrollaban en el correspondiente puerto. Dichos entes, denominados genéricamente "Organizaciones portuarias ${ }^{5}$, surgían como respuesta a la necesidad de descentralizar las funciones ejercidas hasta entonces por la Administración ordinaria del Estado, pretendiendo aproximar las decisiones portuarias a los diferentes niveles locales interesados en el buen funcionamiento y desarrollo de los puertos.

En definitiva, lo que se buscaba era alcanzar una explotación más eficaz del puerto, mediante formas de gestión autónoma que permitieran agilizar los procedimientos de actuación. Y se consideró que eso solo sería posible con la constitución en cada puerto de un organismo local que, dotado de autonomía respecto de la Administración estatal, concentrara todo el grueso de funciones y actividades relativas al gobierno del correspondiente puerto ${ }^{6}$. La primera experiencia de este nuevo modelo de organización tuvo lugar en el año 1903, con la creación del "Consorcio autónomo del Puerto de Génova» ${ }^{\text {? }}$.

La aprobación posterior del Código de la Navegación, y el protagonismo que este atribuía a las autoridades marítimas en la gestión portuaria, no impidió que la nueva modalidad de organización se consolidara, al menos en los principales puertos ${ }^{8}$. De manera que en estos continuaron constituyéndo-

4 E. Stefanini (2009), «Il riparto di competenze tra autorità matittime ed autorità portuali», Quaderni Regionali, 3, págs. 1039-1046. Según el artículo 18 del Código de la Navegación, la Capitanía del Puerto ejercitaba todas las funciones administrativas relacionadas con la navegación y el tráfico marítimo. Tales funciones consistían fundamentalmente en el poder de otorgar concesiones demaniales marítimas, conceder autorizaciones y, en general, proveer sobre todo lo relativo a la seguridad y policía del puerto. Dichas funciones aparecían detalladas en el título III del libro I del Código de la Navegación, relativo a la actividad administrativa, a la policía y a los servicios en los puertos, y eran atribuidas al comandante del puerto.

5 Así los denomina el artículo 1 de la Ley 84/1994.

6 S. M. Carbone (2010), «La c.d. privatizacione dei porti e delle attività portuali in Italia tra disciplina nazionale e diritto comunitario», Il Diritto dell'Unione Europea, 1, págs. 3-4.

7 Ley 50/1903, de 12 de febrero. Algunos años más tarde, el Real Decreto Ley 503/1929, de 14 de marzo, creó el Provveditorato del Puerto de Venecia.

8 Como ha advertido M. Calabró (2011), «Il controverso inquadramento giuridico delle autorità portuali», Il Foro Amministrativo. T.A.R., 9, págs. 295-296, de acuerdo 
se entes portuarios singulares, cada uno definido bajo fórmulas diversas y en función de las características y de las peculiares exigencias del puerto respectivo?. Todos esos entes, sin embargo, compartían un rasgo común: se trataba de sujetos públicos que desempeñaban funciones tanto de carácter administrativo como de carácter empresarial. O por decirlo de otra manera, asumían responsabilidades de administración activa del puerto (regulación, dirección y control de la actividad portuaria) y a la vez desarrollaban actuaciones de carácter netamente económico, ya fueran de explotación directa de las instalaciones portuarias (estaciones marítimas, depósitos de mercancías, medios mecánicos, etc.) o bien de ejercicio y prestación de actividades comerciales y de operaciones y servicios portuarios (por ejemplo, carga y descarga o embarque y desembarque $)^{10}$. Desde esta perspectiva, la doctrina ha resaltado la aparente contradicción que suponía que la regulación de tales entes juntara criterios de funcionamiento típicamente empresariales con una estructura organizativa pública dotada de poderes decisionales administrativos ${ }^{11}$.

Precisamente, la situación de confusión en un mismo sujeto del rol regulador y del rol de agente activo en el mercado de los servicios portuarios ha sido señalada también por la doctrina especializada como una de las principales causas que condujeron a la ineficiencia del sistema portuario, motivada en gran parte, según se ha dicho, por el obstáculo que aquella situación representaba para la libre concurrencia de las empresas que operan en los puertos.

con el Código de la Navegación las competencias sobre la gestión y reglamentación de los puertos correspondía en líneas generales a la Autoridad Marítima. No obstante, tal modelo de administración contemplaba numerosas excepciones, que posibilitaron que sucesivamente, a través de disposiciones especiales, se instituyeran específicos entes portuarios destinados al gobierno de los principales puertos.

9 Ente autónomo del Puerto de Palermo (Ley 1268/1991, de 14 de noviembre); Consorcio para el Puerto de Civitavecchia (Ley 223/1963, de 9 de febrero); Ente autónomo del Puerto de Trieste (Ley 589/1967, de 9 de julio); Ente autónomo del Puerto de Savona (Ley 173/1968, de 1 de marzo); y Consorcio autónomo del Puerto de Nápoles (Decreto-ley 1/1974, de 11 de enero).

10 La heterogeneidad de las funciones atribuidas a los entes portuarios llevó a la jurisprudencia y a la doctrina a encuadrarlos dentro de la categoría de los llamados «entes públicos económicos». De hecho, esta misma calificación aparecía expresamente asignada por las leyes que instituyeron los entes portuarios de Trieste, Nápoles, Venecia y Génova. Sobre la cuestión, puede verse G. Falzea (1992), «Riflessioni sulla natura giuridica e sulle funzioni dell'ente portuale», en VVAA, Studi in Onore di G. Vignocchi, Modena: Mucchi (págs. 579-585).

11 S. M. Carbone (2010: 3-4). 
En este escenario, pues, se hacía necesario acometer una reforma de la legislación portuaria. Y fruto de esa necesidad fue la aprobación de la Ley $84 / 1994$.

\section{LA NECESARIA REORGANIZACIÓN DE LAS ACTIVIDADES EMPRESARIALES DESARROLLADAS EN EL PUERTO}

La Ley de 1994, como pone de manifiesto la lectura de su texto, aborda aspectos diversos de la disciplina portuaria. No obstante, la razón principal que motivó la aparición de aquella se encuentra, según ya se ha dicho, en la necesidad de reorganizar el sistema de explotación de los puertos hacia un modelo de mayor concurrencia y participación de los agentes privados. La libre iniciativa empresarial se veía obstaculizada hasta entonces, por un lado, por la conocida configuración peculiar de los entes portuarios, que aunaban funciones y objetivos de tipo público con modos operativos de carácter netamente empresarial, pero también, por otro lado, igual o más relevante todavía, por la reserva de trabajo portuario que el Código de la Navegación (art. 110) establecía a favor de las "compañías portuarias", en virtud de la cual solo los trabajadores de las mismas podían realizar las tareas vinculadas a las operaciones portuarias ${ }^{12}$.

A la vista de esta situación, ya a finales de los años ochenta y principios de los noventa del siglo anterior se toma plena consciencia de la necesidad de proceder a la modificación de la normativa portuaria. Y de hacerlo en la línea de convertir a los entes portuarios en verdaderas administraciones públicas y, conforme con esto, abrir el mercado de las operaciones y de los servicios portuarios a las empresas privadas ${ }^{13}$. Por lo demás, esta era exactamente la misma

12 Más aún, de acuerdo con el Reglamento para la ejecución del Código de la Navegación (aprobado por Decreto del Presidente de la República 382/1952, de 15 de febrero), solo los nacionales italianos podían participar en las compañías portuarias y, de esta manera, acceder a la realización de las tareas necesarias para el desarrollo de las operaciones portuarias (arts. 152 a 156).

13 Durante este periodo se habían ensayado algunas iniciativas, como la de conceder a algunas empresas portuarias privadas — dotadas de un rol y una función estratégica en el transporte intermodal y con capacidad, por consiguiente, para favorecer el desarrollo de ciertos tráficos de interés para el puerto - la facultad de organizar y gestionar, utilizando en exclusiva determinados espacios portuarios, el ciclo completo de las operaciones portuarias. A tales empresas se les reconocía, en virtud de la llamada «autonomía funcional», la capacidad de adoptar modelos organizativos adecuados a los estándares internacionales, utilizando parámetros y criterios privados de carácter industrial, derogando así algunos condicionantes de corte público, como por ejemplo 
orientación que ya marcaban entonces las normas comunitarias relativas a la competencia y a las libertades de prestación de servicios y de circulación de mercancías. Así pues, en fin, todo parecía confluir hacia un proceso de liberalización de la actividad portuaria. Solo faltaba un pequeño empuje o la chispa que encendiera la mecha para la puesta en marcha de ese proceso. Y de eso se encargó el Tribunal de Luxemburgo, a raíz del enjuiciamiento de la controversia generada por la declaración de servicio público de las operaciones portuarias y de su reserva exclusiva a las compañías portuarias, que acabó estallando en la famosa sentencia "Puerto de Génova»" ${ }^{14}$.

A partir de esta sentencia, el sistema comunitario se convierte en el factor fundamental que impulsará la evolución de la regulación portuaria italiana. En este sentido, poco después de dicha sentencia la Comunicación de la Comisión de 31 de julio de 1992 exhortaba directamente al Gobierno italiano a modificar la disciplina del sector, eliminando, en coherencia con el pronunciamiento del Tribunal de Luxemburgo, la reserva existente a favor de las compañías portua-

el que imponía la reserva del trabajo portuario a las compañías portuarias (S. M. Carbone, 2010: 5-8).

14 Sentencia del TJCE de 10 de diciembre de 1991 (c-179/90, Siderurgica Gabrielli c. Merci Convenzionali Porto di Genova). El Tribunal de Génova había justificado el reenvío prejudicial al Tribunal de Luxemburgo alegando que el desembarco de las mercancías podía haberse realizado por el personal de la embarcación a coste inferior, y que el recurso obligatorio al servicio de las dos empresas titulares del derecho exclusivo había comportado costes suplementarios que consecuentemente incidían sobre el precio de las mercancías y, por lo tanto, sobre las condiciones de la importación. A la vista de esta alegación no le fue difícil al Tribunal de Justicia condenar la ilegalidad de la discriminación establecida a favor de las compañías portuarias italianas. Sin embargo, más allá de eso, la sentencia se encargó también de poner de relieve la plena aplicabilidad de las normas comunitarias de la competencia al sector de las operaciones portuarias y del trabajo portuario, condenando la incompatibilidad de las previsiones del Código de la Navegación con las normas del Tratado, en la medida que aquellas habilitaban un régimen de monopolio que cerraba el mercado a las empresas interesadas en prestar o recibir servicios comprensivos del ciclo unitario de las operaciones portuarias. Un comentario de la sentencia comunitaria puede verse en $\mathrm{F}$. Munari (1991), «Compagnie portuali, imprese concesionarie e operazioni di imbarco e sbarco. Il diritto comunitario e la Corte di Giustizia», Diritto Marittimo, págs. 1129-1141. Por otra parte, sobre la compatibilidad de la regulación portuaria italiana con la normativa comunitaria se puede ver, entre otros, S. M. Carbone y F. Munari (1996), «Gli effetti del diritto comunitario sulla riforma portuale in Italia. I risultati e le prospettive», Diritto dei trasporti, págs. 5606-5612; también, P. Mengozzi (1995), "Regime delle operazioni portuali. Codice della Navigazione e diritto comunitario", en VVAA, Studi in onore di A. Levebre D’Ovidio, Milano, págs. 731-750. 
rias y cualquier otra forma de monopolio que no viniera justificada por la falta de oferta suficiente ${ }^{15}$. La intervención del legislador parecía inaplazable ${ }^{16}$. Y así se produjo, finalmente, con la Ley de 28 de enero de 1994.

En resumidas cuentas, la confrontación con la normativa comunitaria en materia de competencia, la situación de conflictividad de intereses creada por la concurrencia en los entes portuarios de funciones regulatorias y de explotación y, en definitiva, la situación de grave ineficiencia del sistema que todo ello provocaba, son las razones que llevaron al legislador italiano a abordar, a través de la Ley 84/1994, una profunda reforma en la definición del modelo de administración y explotación de los puertos.

\section{LA LEY DE 28 DE ENERO DE 1994}

\section{LA ADMINISTRACIÓN PORTUARIA: AUTORIDADES PORTUARIAS Y AUTORIDADES MARÍTIMAS}

El objetivo principal perseguido por la Ley de 1994 ha sido la introducción en el sistema portuario del modelo de landlord port authority, que implica la asignación a un sujeto público de las funciones de programación, dirección y control de la actividad portuaria y que deja en manos de los sujetos privados

15 Según se expresaba en la Comunicación, los servicios prestados por la compañías portuarias no podían calificarse, habida cuenta la modalidad y contexto en el que se desarrollaban, como "servicios de interés económico general», en el sentido del entonces vigente artículo 90 TCE, hoy 106 TFUE. O por decirlo de otra manera, la Comunicación: i) por un lado, legitimaba el llamado «derecho de autoproducción» (self-handling) de las operaciones portuarias por parte de las empresas de transporte marítimo comunitarias, en base a las normas de la libre competencia y de las libertades de prestación de servicios y de circulación de mercancías; y ii) por otro lado, condenaba la existencia de artificiosas formas de monopolio en aquellos casos en que es posible, e incluso resulta más eficaz desde el punto de vista de los usuarios, la concurrencia en el mercado portuario de una pluralidad de empresas.

16 El Consejo de Estado, en su resolución de 13 de mayo de 1992, ya había alertado, a raíz del pronunciamiento del Tribunal de Luxemburgo, de la confrontación existente entre el derecho interno y el derecho comunitario. Es más, había declarado la inaplicabilidad de las normas internas que resultaran contradictorias con el derecho comunitario. Sin embargo, consciente de la complejidad y delicadeza de la situación derivada del desplazamiento de las normas internas, la resolución estimaba jurídicamente oportuno una intervención legislativa específica de reforma entera del sistema, destinada a compatibilizarlo con las determinaciones del TCE. 
la realización de todas las tareas directamente vinculadas y necesarias para el desarrollo del tráfico portuario ${ }^{17}$.

A tal efecto, la novedad fundamental que introduce la Ley de 1994 ha consistido en la institución de las denominadas "Autoridades Portuarias», que aparecen en sustitución de los viejos entes portuarios, y que se configuran como sujetos públicos encargados básicamente de la función pública de administración y gestión de los diferentes puertos. Por su parte, la prestación de las operaciones y servicios portuarios y el ejercicio de las diferentes actividades comerciales o industriales queda a disposición de los operadores privados, en un ámbito de mercado competitivo. En este sentido, precisamente, el artículo 6 de la Ley dispone que las Autoridades Portuarias tienen personalidad jurídica pública y están dotadas de autonomía administrativa, financiera y presupuestaria, y que a ellas corresponde la función de dirección, programación, coordinación, promoción y control de las operaciones portuarias y de las actividades comerciales e industriales realizadas en el puerto.

No obstante, debemos advertir que la implantación legal del modelo de administración a través de la Autoridad Portuaria no se realiza de forma generalizada, es decir, para la totalidad de los puertos, sino que queda circunscrito a los de mayor relevancia por razón de su tráfico o actividad económica. Al respecto, conviene destacar: i) en primer lugar, el apartado 1 del artículo 6 de la Ley, en el que se establece la relación de puertos en los que se instituye directamente la figura de la Autoridad Portuaria ${ }^{18}$; ii) en segundo lugar, el apartado 8 del mismo artículo 6 , donde se definen los requisitos exigidos a los puertos, en relación a su tráfico, para que puedan constituirse nuevas Autoridades Portuarias ${ }^{19}$; y iii) en tercer lugar, por último, el artículo 4 , en el que se establece la clasificación de los puertos según la importancia de su actividad

17 E. Musso y C. Ferrari (2009), "Verso la reforma portuale», Quaderni Regionali, 3, págs. 991-1005.

18 Los puertos son los siguientes: Ancona, Bari, Brindisi, Cagliari, Catania, Civitavecchia, Génova, La Spezia, Livorno, Marina di Carrara, Messina, Nápoles, Palermo, Ravena, Savona, Taranto, Trieste y Venecia. Posteriormente a la Ley de 1994 fueron instituidas las Autoridades Portuarias de: Piombino (1996), Gioia Tauro (1998), Salerno (2000), Olbia y Golfo Aranci (2000) y Augusta (2001). Finalmente, en el año 2003 se crearon las Autoridades Portuarias de Trapani y Manfredonia, aunque ambas fueron posteriormente suprimidas, en el año 2007.

19 Según se dispone en este precepto, mediante Decreto del Presidente de la República se pueden instituir nuevas Autoridades Portuarias, en los puertos de categoría II, clases I y II, que durante el último trienio hayan registrado un volumen de tráfico de mercancías no inferior a tres millones de toneladas anuales al neto del $90 \%$ de los graneles líquidos o a 200000 TEU (Twenty Feet Equivalent Unit). 
económica, y donde se dispone que la sede de las Autoridades Portuarias deberá corresponder a puertos de relevancia económica nacional o internacional ${ }^{20}$.

Como habíamos dicho antes, las Autoridades Portuarias han sustituido a los viejos entes portuarios que se habían creado singularmente para la gestión de determinados puertos, pero en ningún caso han hecho desaparecer a la Administración marítima. Al contrario, en aquellos puertos en los que no se ha instituido la Autoridad Portuaria el papel y protagonismo que desempeñan las autoridades marítimas en la administración portuaria sigue siendo de primer orden. Y en los restantes puertos, esto es, en los que sí existen Autoridades Portuarias, estas y las autoridades marítimas se reparten las responsabilidades sobre la gestión del puerto y la dirección de las operaciones y servicios portuarios.

La Ley de 1994 dedica un artículo específico, el 14, a definir las atribuciones de las autoridades marítimas. No obstante, la delimitación de las competencias que corresponden a estas frente a las de las Autoridades Portuarias no resulta, a la vista de la Ley, una tarea fácil o sencilla, por la razón de que una parte importante de las responsabilidades asumidas por las Autoridades Portuarias incide directamente sobre materias que hasta entonces habían estado reguladas por el Código de la Navegación. En este sentido, el artículo 14.1, tras afirmar que son propias de las autoridades marítimas las funciones de policía y seguridad previstas en el mencionado Código de la Navegación y en las leyes especiales, incluidas las correspondientes actividades administrativas, se encarga de precisar que todas esas atribuciones se han de entender en todo caso «sin perjuicio de las competencias otorgadas por la presente ley a las Autoridades Portuarias» ${ }^{21}$.

20 Los puertos se clasifican en dos categorías: I, para los puertos vinculados a la defensa militar o a la seguridad del Estado, y II, para los puertos destinados a la actividad comercial. Dentro de esta última categoría se distinguen a su vez tres clases: I, puertos de relevancia económica internacional; II, puertos de relevancia económica nacional; y III, puertos de relevancia económica regional e interregional.

21 Como excepción a la formulación general del apartado 1 del artículo 14, en los apartados 1 bis y 1 ter del mismo precepto se reconoce de manera concreta la competencia de las autoridades marítimas sobre la disciplina y organización de los servicios técnico-náuticos, o sea, los servicios de practicaje, remolque, amarre y desembarco (sin atraque, ferrying), siempre, eso sí, de conformidad con las Autoridades Portuarias. Los servicios técnico-náuticos son servicios, distintos de las operaciones portuarias, que se prestan a las embarcaciones con motivo de su llegada o salida del puerto y que tienen como objetivo garantizar la seguridad de la navegación y del propio puerto y zonas adyacentes. Por esa razón, precisamente, que se reconozcan a las autoridades marítimas especiales atribuciones en relación a los mismos, particularmente para el 
Como solución interpretativa, la doctrina ha señalado que el complejo de poderes otorgados a las Autoridades Portuarias está fundamentalmente orientado al cumplimiento de las funciones de dirección, coordinación y control de las operaciones portuarias y otras actividades comerciales e industriales que se realizan en el puerto. En cambio, las atribuciones de las autoridades marítimas están dirigidas a un objetivo distinto, básicamente el de garantizar la seguridad de la navegación. En definitiva, pues, el reparto de competencias entre autoridades portuarias y marítimas responde sobre todo a un criterio funcional, partiendo de la base de que unas y otras están institucionalmente encargadas de atender a intereses distintos ${ }^{22}$. De este modo, incluso en el supuesto de que la Ley de 1994 atribuya expresamente a las Autoridades Portuarias funciones que corresponden según el Código de la Navegación a las autoridades marítimas, la delimitación de las competencias de unas y otras ha de hacerse entendiendo que aquella atribución queda limitada a las tareas propias de la función institucional que corresponde a las Autoridades Portuarias ${ }^{23}$.

Como ha advertido la doctrina, la aplicación del criterio funcional permite identificar y establecer una lista de las principales responsabilidades portuarias que continúan en manos de las autoridades marítimas, incluso en el supuesto de puertos en los que se hayan instituido Autoridades Portuarias: se trata especialmente de todas aquellas funciones previstas y reguladas por el Código de la Navegación que afectan a la seguridad de las operaciones que se desarrollan en las aguas del puerto, o que afectan a otras operaciones que, aun realizándose sobre el espacio terrestre, tienen una incidencia directa sobre la seguridad de la navegación ${ }^{24}$.

establecimiento de las obligaciones de servicio público que se asocian a su prestación mediante específicas reglamentaciones establecidas en cada puerto. Sobre el régimen de tales servicios puede verse S. M. Carbone y F. Munari (1995), «I servizi portuali ancillari alla navigazioni tra esigenze di sicurezza e regole di mercato», Diritto marittimo, págs. 916-941.

22 Sobre esta cuestión, puede verse R. Tranquilli-Leali (1999), «Le funzioni organizzative e di ordinanza delle autorità portuali», Dirito dei trasporti, págs. 569-577.

23 Así sucede, por ejemplo, en el artículo 8.3.h), donde se atribuye al presidente de la Autoridad Portuaria la administración de las áreas y bienes de dominio público, «ejercitando, oído el Comité Portuario, las atribuciones establecidas en los artículos 36 a 55 y 68 del Código de la Navegación».

24 E. Stefanini (2009: 1039-1046) ha señalado las siguientes, de las previstas en el Código de la Navegación: i) funciones relativas al movimiento de las embarcaciones, incluida la fijación del orden de atraque en el muelle (arts. 62-63); ii) reglamentación y disciplina de las embarcaciones destinadas al servicio de los puertos (arts. 66-67); iii) socorro a las naves en peligro de naufragio (arts. 69-70); iv) disciplina de la pesca 


\section{ADMINISTRACIÓN PÚBLICA Y EXPLOTACIÓN PRIVADA. EL MERCADO DE LOS SERVICIOS Y LAS OPERACIONES PORTUARIAS}

Según ya se ha indicado antes, en el modelo introducido por la Ley 84/1994 las Autoridades Portuarias se presentan como sujetos «reguladores» cuya función esencial ha de ser la de administrar las actividades de empresa que se desarrollan en el ámbito portuario, seleccionando -mediante el otorgamiento de autorizaciones y concesiones - a los operadores que pretenden acceder al mercado y controlando que se respeten los niveles mínimos de calidad exigidos a aquellas actividades y los intereses públicos implicados en el desarrollo del tráfico portuario. Dicho en otras palabras, en la mente del legislador de 1994 estaba la idea clara de atribuir a las Autoridades Portuarias un auténtico rol de administrador autónomo e imparcial de los bienes y de las actividades vinculadas a la explotación portuaria. Y asimismo, la idea de que dicho rol debían desempeñarlo con el ejercicio de una doble función, la de regulación y control del mercado competitivo de las actividades portuarias y la de promoción de la eficiencia y competitividad del ámbito portuario ${ }^{25}$. En esta línea se enmarcan las funciones que la Ley (art. 6.1) atribuye a las Autoridades Portuarias ${ }^{26}$, así como también la configuración que hace de las mismas como sujetos de derecho público (art. 6.2).

La separación entre actividad de regulación, asignada a las Autoridades Portuarias, y actividad empresarial, confiada a la iniciativa privada, pretende ser rigurosa, hasta el punto de que la Ley de 1994 prohíbe expresamente que aquellas puedan desarrollar — directamente o a través de participación en sociedades - operaciones portuarias u otras actividades estrechamente conexas

en los puertos (art. 79); v) reglamentación de la utilización de armas y encendido de fuego en los puertos (art. 80); vi) funciones de policía del puerto (art. 81), interviniendo en caso de desorden en el puerto o sobre las embarcaciones (art. 82). A todas estas funciones cabe añadir la relativa al otorgamiento de autorizaciones para las operaciones de embarque, desembarque y transbordo de mercancías peligrosas; y, asimismo, la referida a la disciplina y organización de los servicios técnico-náuticos.

25 Como ha destacado M. Maresca (2006), La governance dei sistema portuali. Linee di una reforma di diemnsione europea, Bolonia: Il Mulino (pág. 34), las Autoridades Portuarias acaban por desarrollar una doble función pública, siendo encargadas de cumplir, por un lado, una función de regulación y control, y por otro lado, una función de promoción o, lato sensu, de política de los transportes (marketing territorial, selección de infraestructuras, promoción de las redes, etc.).

26 Para un análisis de las diversas funciones confiadas a las Autoridades Portuarias puede verse G. Acquarone (2008), «Le attività di promozione, programmazione e regolamento delle Autorità portuali», Diritto Marittimo, págs. 703-782. 
(art. 6.6), o hasta el punto de que la Ley dispone también que las actividades de mantenimiento de las partes comunes del puerto y de prestación a los usuarios del mismo de servicios de interés general no pueden llevarse a cabo directamente por los entes portuarios, sino que han de hacerse efectivas a través del sistema de concesión —-mediante concurso público- a terceros [art. 6.5 en relación al art. 6.1.b) y c)].

En realidad, como podremos comprobar más adelante, la separación pretendida por la Ley no es tan estricta como aparenta. En cualquier caso, este propósito es el que explica la atención detallada que la norma de 1994 dedica a la regulación del sistema de acceso de los sujetos privados al mercado portuario.

La regulación de la Ley de 1994 permite distinguir varias categorías de actividades relacionadas con el tráfico portuario ${ }^{27}$. En primer lugar, las denominadas «operaciones portuarias», que según el artículo 16.1 son las siguientes: la carga y descarga, el transbordo, el depósito y, en general, el movimiento de las mercancías y otros materiales en el interior del ámbito portuario. $Y$ en segundo lugar, distinta de la anterior, la categoría de los llamados «servicios portuarios», dentro de la cual se pueden diferenciar a la vez distintas modalidades: i) por un lado, los servicios portuarios en sentido amplio, definidos en el artículo 16.1 como aquellas actividades de prestación específicas, complementarias y accesorias al ciclo de las operaciones portuarias ${ }^{28}$; ii) por otro lado, los servicios técnico-náuticos, esto es, según el artículo 14.1bis, el practicaje, el remolque, el atraque y el desembarco (ferrying) ${ }^{29}$; y iii) finalmente, los que la Ley califica, en el artículo 6.1.c), como servicios de interés general, respecto de los cuales simplemente señala que no son coincidentes ni están estrechamente conexos con las operaciones portuarias ${ }^{30}$.

27 Véase, al respecto, E. Santoro (2007), «I servizi e le operazioni portuali», en A. Antonini (coord.), Trattato breve di diritto marittimo, Milán: Giuffrè (págs. 242-260). El artículo 2 del Decreto Ministerial 132/2001, de 6 de febrero, define el «ciclo de operaciones portuarias» como el conjunto de operaciones de carga, descarga, transbordo y, en general, movimiento de las mercancías y otros materiales en el ámbito portuario realizadas por las empresas autorizadas, y dirigidas a trasladar la carga o una parte de la misma desde la embarcación a otra modalidad de transporte (o viceversa). Véase nota 20 ut supra.

30 El artículo 6.1.c) de la Ley de 1994 dispone que la identificación de estos servicios se efectuará mediante Decreto del Ministerio de los Transportes y de la Navegación. De este modo, el Decreto Ministerial de 14 de noviembre de 1994 (posteriormente modificado por la Ley 47/1996) señaló los siguientes servicios: iluminación, limpieza y recogida de residuos, suministro de agua, mantenimiento y reparación de embar- 
Todas las actividades señaladas anteriormente quedan residenciadas por la Ley dentro del proceso liberalizador impulsado por esta, incluso los servicios técnico-náuticos disciplinados y organizados por las autoridades marítimas, si bien es cierto que la naturaleza de tales servicios comporta que su prestación se realice normalmente en régimen de monopolio (privado) ${ }^{31}$.

Así las cosas, en fin, podríamos decir que en el ámbito portuario se desarrollan paralelamente varios mercados. A saber. Por una parte, el mercado de los operadores de terminales, esto es, de los que desarrollan operaciones portuarias sirviéndose de la infraestructura y superestructura fijas. Y por otro lado, el mercado de los servicios portuarios, es decir, de las empresas que prestan servicios al terminalista o, en su caso, directamente a los usuarios del puerto. Según el artículo 16.3 de la Ley, la realización de operaciones portuarias y la prestación de servicios portuarios, ya sea por cuenta propia o de terceros, está sometida a autorización de las Autoridades Portuarias, o de las autoridades marítimas si no se hubiera instituido el ente portuario. Y según el artículo 18.1, corresponde a las Autoridades Portuarias, o a las autoridades marítimas en caso de inexistencia de aquellas, el otorgamiento en concesión de las áreas demaniales y de los muelles a las empresas autorizadas — ex art.

caciones, servicios informáticos y telemáticos, estaciones marítimas y asistencia a los pasajeros y servicios comunes al sector industrial y comercial del puerto.

31 S. M. Carbone (2010: 18-19). Como ha señalado este autor, la naturaleza de los servicios técnico-náuticos y la imposición respecto a los mismos de específicas obligaciones de servicios público justifican que su prestación se realice en régimen de monopolio, que se entiende como el «modelo microeconómico más adecuado» (en este sentido, entre otras, la sentencia del T.A.R. Lazio de 12 de enero de 1996). Según advierte también el autor citado, la existencia de una única empresa prestadora permite la puesta en juego del llamado «mínimum optimal scale». O por decirlo de otra manera, si existiera una pluralidad de empresas prestadoras éstas no podrían producir un «output» inferior al del monopolista, lo que comportaría que los costes unitarios de prestación del servicio serían mayores, o bien que se reducirían las inversiones realizadas para la prestación, con las consiguientes consecuencias negativas, en un caso y en el otro, sobre el precio a satisfacer por los usuarios o sobre la seguridad de la navegación. Por su parte, la jurisprudencia comunitaria (véase, entre otras, la Sentencia del TJCE de 18 de junio de 1998, Corsica Ferries c. Gruppo Antichi Ormeggiatori del Porto di Genova) ha reconocido que los servicios técnico-náuticos tienen características de servicio público que los permiten reconducir al ámbito del artículo 86.2 TCE (hay 106.2 TFUE), en función de la universalidad de la oferta, la continuidad de su prestación y la satisfacción de los intereses públicos de la navegación, además del papel determinante que corresponde a la Administración pública respecto a su reglamentación, control y disciplina. 
16.3 - para la realización de las operaciones portuarias y la prestación de los servicios portuarios.

A pesar de que la referencia que el artículo 18.1 hace al artículo 16.3 puede generar cierta confusión, el cuadro operativo que diseña la Ley de 1994 para el acceso al mercado de las actividades portuarias resulta relativamente sencillo, y se basa en el juego de dos títulos distintos: la «autorización», para el ejercicio de operaciones y servicios portuarios ${ }^{32}$, y la "concesión», para la ocupación de las áreas de dominio público necesarias para la realización y prestación de las mencionadas operaciones y servicios ${ }^{33}$. Ambos títulos pue-

32 Tal como señala el artículo 16, la autorización comprende el desarrollo de operaciones portuarias o de uno o más servicios portuarios (especificados en la misma autorización). Para el otorgamiento de las autorizaciones, por parte de las Autoridades Portuarias o marítimas, corresponde al Ministerio competente determinar: i) los requisitos - personales, profesionales, técnico-organizativos y de capacidad financiera- que deben reunir los operadores y empresas solicitantes, y que deben ser adecuados a las actividades que se pretenden desarrollar; ii) los criterios, las formas y los plazos relativos al otorgamiento, suspensión o revocación de los actos de concesión, así como a los correspondientes al control de tales actos; iii) los parámetros para definir los límites mínimos y máximos del canon anual que deben satisfacer los titulares de la autorización, en relación a la duración y especialidades de la autorización y teniendo en cuenta el volumen de las inversiones y de la actividad a llevar a cabo; y iv) los criterios específicos en orden al otorgamiento de autorizaciones para operaciones portuarias a realizar a la llegada o salida de embarcaciones dotadas de medios y personal propios para llevarlas a cabo (autoproducción). La autorización tendrá la duración prevista en el programa operativo propuesto por la empresa interesada, y podrá ser renovada al compás de un nuevo programa operativo (o de la concesión, cuando la autorización esté ligada a la utilización de estructuras fijas). Finalmente, corresponde a las Autoridades Portuarias, o en su caso marítimas, determinar —oída la Comisión consultiva local- el número máximo de autorizaciones que se pueden otorgar, en relación «a las exigencias de funcionalidad del puerto y del tráfico», debiendo asegurarse en todo caso el máximo de concurrencia en el sector (la limitación de autorizaciones no afecta a los supuestos de autoproducción). S. M. Carbone (2010: 12-14) ha criticado el uso de la expresión transcrita como criterio para la limitación del número de autorizaciones, en la medida que entiende que tal criterio expresa una lógica programadora de tipo dirigista. Según el mencionado autor, la limitación de autorizaciones, sea cuantitativa (número de licencias) o cualitativa (tipo de tráficos), debería basarse siempre en circunstancias objetivas, vinculadas a la disponibilidad de espacio o de protección del medio ambiente.

33 El artículo 18 establece que las concesiones serán otorgadas, por parte de las Autoridades Portuarias o marítimas y previa determinación del correspondiente canon, considerando la entidad del tráfico portuario que se pretende desarrollar. Correspon- 
den concurrir perfectamente en un mismo sujeto. En este sentido, el artículo 16 establece que si la empresa titular de una autorización lo fuera también de una concesión, entonces la duración del primer título será igual a la del segundo. Y el artículo 18, por su parte, dispone que la empresa concesionaria ha de ejercitar directamente las actividades en atención a las cuales ha obtenido la concesión ${ }^{34}$. No obstante, cabe admitir también que uno y otro títulos puedan

de al Ministerio competente: i) establecer la duración de las concesiones, los poderes de vigilancia y control de la Autoridad concedente y la forma de renovación de las concesiones; y ii) determinar los límites mínimos del canon que deben satisfacer los concesionarios. Igualmente corresponde al Ministerio señalar los criterios que deben seguir las Autoridades concedentes a fin de que en el ámbito portuario se reserve espacio operativo suficiente para el desarrollo de operaciones portuarias por parte de empresas que no son titulares de concesiones. Para el otorgamiento de las concesiones se exige que el solicitante presente un programa de actividades adecuado para la mejora del tráfico y de la productividad del puerto; asimismo, se exige que disponga de adecuados medios técnicos y productivos; y, por último, que prevea una organización de los trabajadores conforme al programa de actividad. La Autoridad Portuaria, o marítima, debe verificar, al menos anualmente, el mantenimiento de los requisitos en base a los cuales se otorgó la concesión, así como también el correcto desarrollo del programa de actividades. En caso de incumplimiento de las obligaciones asumidas, la concesión podrá ser revocada.

34 G. Taccogna (2009), «L'assentimento dei terminal portuali: riparto de la potestà normativa tra stato e regioni; procedure e criteri di aggiudicazione», Quaderni Regionali, 3, págs. 964-966, ha criticado el modo en que la Ley establece la relación concesión-autorización. A juicio del autor, la problemática surge del hecho de que tanto el artículo 18 como el artículo 16 exigen, como ya sabemos, que el solicitante presente un programa operativo o de actividad. Así las cosas, el autor entiende que no resulta razonable pensar en una doble valoración para obtener la autorización de actividad, primero, y la concesión para la ocupación, después, tratándose, además, de dos procedimientos distintos. Dada la redacción de la Ley, que prevé que la concesión sea otorgada a las empresas autorizadas, lo lógico es pensar que en el programa de la autorización han de aparecer ya identificadas e individualizadas las áreas sobre las cuales se llevará a cabo la actividad. Esto conlleva, por lo tanto, en opinión del autor, que la elección entre los pretendientes a las áreas demaniales deba hacerse ya en el procedimiento de autorización, sin perjuicio de que el autorizado deba someterse luego al procedimiento de autorización. En cualquier caso, si eso fuera así, ello provocará que la segunda valoración del programa quede absorbida por la primera; y lo que es más importante, que en el procedimiento de concesión no pueda haber una verdadera concurrencia, toda vez que solo podrá optar a la concesión el titular de la autorización que prevea operar en las concretas áreas a conceder. Según el autor, la problemática denunciada no ha sido detectada por la doctrina, que no ha tenido ningún impedi- 
corresponder a sujetos distintos. O lo que es lo mismo, que el concesionario pueda encargar a un tercero, una empresa debidamente autorizada, la realización de concretas actividades integradas dentro del ciclo de las operaciones portuarias. En resumidas cuentas, lo que quiere decirse es que, además del terminalista, titular de la concesión, que desarrolla operaciones y presta servicios a través de una estructura fija, existen también otros operadores portuarios, los que integran el llamado «segundo mercado», esto es, las empresas que ofrecen al terminalista o a los usuarios del puerto sus propios servicios sin disponer de una estructura fija de muelles o terminales ${ }^{35}$.

En realidad, para ser exactos, el mercado de los operadores de terminales y el mercado de los prestadores de servicios portuarios no son los únicos que actúan sobre el ámbito portuario, sino que a estos dos debe sumarse un tercero: el mercado del suministro de mano de obra especializada a las empresas encargadas de la ejecución de las operaciones y servicios portuarios.

Sobre este particular mercado, ya conocemos cuál era la situación existente antes de la Ley de 1994, cuando el suministro de mano de obra portuaria estaba monopolizado por las denominadas «compañías portuarias». Pues bien, la Ley 84/1994 ha querido también afrontar la reforma del trabajo portuario, con el objetivo igualmente de abrir dicho mercado a la libre concurrencia. A la realización de este propósito obedecen fundamentalmente las previsiones contenidas en el artículo 17, y también, un poco más adelante, las recogidas en el artículo 21, donde se impone la conversión de las viejas compañías portuarias

mento en entender que la remisión que el artículo 18.1 efectúa al artículo 16.3 debe interpretarse del modo que la autorización para el ejercicio de operaciones y servicios portuarios se configura en la intención del legislador como un presupuesto para el otorgamiento de la concesión [véase G. Ingratoci (2007), «La concessione di aree e banchine», Diritto Marittimo, 4, págs. 989-1009]. A juicio del autor, la solución del problema pasaría por integrar los dos procedimientos en uno solo.

35 Véase lo dicho en la nota 32 respecto a la necesidad de reservar espacios operativos suficientes para que las empresas no concesionarias puedan desarrollar operaciones y servicios portuarios. Por otra parte, si bien es cierto que el artículo 18 establece que el concesionario debe ejercitar directamente las actividades en atención a las cuales ha obtenido el título, también es cierto que la jurisprudencia (véase, por ejemplo, la Sentencia del T.A.R. Puglia de 24 de enero de 2002), y más tarde la propia normativa (Ley 172/2003), han admitido que algunos servicios o fases de la actividad portuaria puedan ser confiados por el concesionario a terceras personas, previa solicitud motivada por parte de aquel — dirigida a la Autoridad concedente - que se ampare en razones justificadas (por ejemplo, específicas exigencias de especialización para la prestación del servicio, carencias temporales de profesionalidad en la estructura orgánica del concesionario, etc.). 
en sociedades o entidades cooperativas. Según la regulación introducida por la Ley, el trabajo portuario ha dejado de ser considerado como un servicio público, para pasar a concebirse como una verdadera actividad empresarial desarrollada — en virtud de la correspondiente autorización — bajo el control de la Administración pública. Así pues, las antiguas compañías, hoy reconvertidas, actúan en régimen de concurrencia con otras empresas para el suministro de trabajadores portuarios ${ }^{36}$. No obstante, hay que advertir que, según resulta del régimen legal, la actividad de prestación de mano de obra debe realizarse en el puerto por una sola empresa. Eso significa, pues, que tal empresa asumirá en el mercado una posición de monopolio, aunque en este caso derivada de un proceso selectivo en pública concurrencia. En definitiva, de una situación de mercado cerrado y sin competencia se ha pasado a una situación de competencia para el acceso al mercado.

Finalmente, como cláusula de garantía, para el caso de inexistencia o insuficiencia de oferta de mano de obra, la Ley prevé que el déficit de empresas suministradoras podrá ser sustituido por la iniciativa de la Autoridad Portuaria, facultada en tal caso para la creación de una agencia que asuma la actividad de suministro de trabajadores portuarios.

\section{LA DISCUTIDA NATURALEZA DE LAS AUTORIDADES PORTUARIAS: SUS ACTIVIDADES ECONÓMICAS}

Pese a todo lo dicho anteriormente, hay que advertir, según ya hemos avanzado en otro momento, que el principio de separación entre actividad reguladora y actividad empresarial no siempre aparece en la Ley en unos términos absolutamente claros y precisos, algo que ha motivado la crítica de todos aquellos que esperaban ver en la norma legal un paso inequívoco hacia la «privatización» de la actividad portuaria ${ }^{37}$. En otras palabras, la lectura del texto legal pone de manifiesto la existencia de disposiciones que atribuyen a las Autoridades Portuarias poderes y tareas mediante las cuales su interven-

36 En efecto, según se desprende de la regulación legal, las compañías portuarias se han de transformar en sociedades o entidades cooperativas, capacitadas para concurrir a la realización de las operaciones portuarias y a la prestación de los servicios portuarios. Asimismo, dichas sociedades o entidades podrán optar también, mediante concurso y la oportuna autorización, al ejercicio de la actividad de prestación de mano de obra a las empresas operadoras en el puerto. En tal caso, sin embargo, aquellas sociedades o entidades solo podrán dedicarse a esta última actividad, esto es, la de suministro de mano de obra, debiendo renunciar o deshacerse de cualquier participación — directa o indirecta - en la actividad de prestación de operaciones o servicios portuarios.

37 Así lo ha puesto de manifiesto S. M. Carbone (2010: 12-14). 
ción en el mercado portuario no se limita al papel de sujeto neutral, sino que alcanza al de un verdadero operador, prestador de servicios en régimen de concurrencia, cuando no incluso en situación de monopolio. Los preceptos que centran la atención en este sentido son fundamentalmente dos.

En primer lugar, el artículo 6.6, donde se prevé la posibilidad de que las Autoridades Portuarias constituyan —o participen - sociedades que ejerzan actividades accesorias o instrumentales respecto a los fines institucionales confiados a las mismas, aunque ello solo a los efectos de la promoción y el desarrollo de la intermodalidad, la logística y las redes de transporte. La disposición puede parecer de escasa relevancia. Sin embargo, como ha destacado la doctrina, la intermodalidad, la logística y las redes de transporte sin duda constituyen factores esenciales para el desarrollo y competitividad de los puertos $^{38}$. Y en este sentido, la doctrina ha criticado que se haya otorgado a las Autoridades Portuarias un verdadero rol de «parte» en relación a esos factores $^{39}$, cuando la responsabilidad que mejor congeniaría con su naturaleza de entes reguladores sería la de promotor de la síntesis de los diversos intereses — públicos y privados — implicados, desarrollando una atenta programación y vigilancia de las actuaciones que, en régimen de concurrencia, los inversores pretendan llevar a cabo ${ }^{40}$.

38 En este sentido, M. Calabró (2011: 2930-2931).

39 Por otra parte, la previsión contenida en el artículo 6.6 ha sido utilizada en ocasiones por las Autoridades Portuarias como fundamento para el desarrollo de actividades distintas de las estrictamente permitidas. Así lo ha destacado el Tribunal de Cuentas, que en su labor de fiscalización de la gestión financiera de las Autoridades Portuarias ha denunciado cómo la invocación del artículo 6.6 ha servido a aquellas para justificar la titularidad de participaciones accionariales no permitidas, es decir, referidas a sociedades que desarrollan actividades económicas que no son accesorias o instrumentales respecto a los fines institucionales atribuidos a las Autoridades Portuarias. Como ejemplo, puede citarse el pronunciamiento (núm. 109/2010) derivado del control efectuado sobre la gestión financiera de la Autoridad Portuaria de Trieste (ejercicios 2007-2008), donde se pone de manifiesto que dicho ente había adquirido participaciones sociales de una sociedad concesionaria de una terminal, siendo que la misma Autoridad Portuaria era la que había otorgado la concesión.

40 Como han destacado O. Baccelli y A. Tedeschi (2009), «Il ruolo delle Autorità Portuali: scenari per la promozione dell'intermodalità e l'autonomia finanziaria», Quaderni Regionali, 3, págs. 1058-1063, la competitividad de un puerto no está ligada únicamente a la localización geográfica, es también a la calidad de los servicios ofrecidos. Es fundamental, pues, la presencia de instalaciones y medios adecuados para el movimiento de las mercancías que permitan cumplir de manera rápida las operaciones de embarco/desembarco y de transferencia de la carga desde una modalidad a 
Y en segundo lugar, más importante todavía, el artículo 23.5, que dispone que las Autoridades Portuarias que se hubieran constituido allí donde antes existían Organizaciones Portuarias podrán prestar todos o parte de los servicios de interés general que venían prestando estas. Y ello a través de la constitución de una o varias sociedades con las empresas operantes en el puerto, si bien en ningún caso la participación del ente portuario podrá ser mayoritaria. Hay que advertir, al respecto de la posibilidad que ofrece la Ley, que los servicios de interés general pueden coincidir con actividades que con frecuencia son muy relevantes en el ámbito de la vida portuaria y, sobre todo, con actividades económicas que se realizan a título oneroso. No obstante, la doctrina ha intentado limitar el alcance de la previsión contenida en el artículo 23.5, advirtiendo que la prestación de los servicios mencionados no constituye una obligación para las Autoridades Portuarias, sino una simple facultad, lo que permite entender que la ratio de la norma está orientada a que la intervención de aquellas se produzca con carácter subsidiario, esto es, en defecto de mercado ${ }^{41}$.

Sea como fuere, la participación de las Autoridades Portuarias en actividades de corte empresarial o comercial ha suscitado un importante debate sobre la naturaleza jurídica de tales entes, sin que hasta el momento se haya llegado a una solución unánime o pacífica sobre la cuestión.

otra, así como también la existencia de conexiones directas con los principales mercados de origen o destino de las mercancías transportadas. Para hacer eficiente un área portuaria es necesario tomarla en consideración dentro de un sistema más amplio de transporte que permita interacciones con otros sistemas portuarios y con el sistema de transporte terrestre. Los puertos, en fin, han de ser considerados parte integrante del supply chain, de manera que el criterio de elección de un puerto estará basado sobre el entero servicio de transporte ofrecido, con el objetivo de minimizar los costes totales del mismo. Desde esta perspectiva, surge entonces la idea de las Autoridades Portuarias como port cluster manager, capaces de desarrollar estrategias generadoras de recursos para inversión, sobre todo mediante partnership y coordinación entre los diferentes agentes presentes en el cluster portuario.

41 F. Munari (2004), "La trasformazione dei porti da aree demaniali portuali a mercati: amministrazione e gestione delle aree portuali tra sussidiarietà e privatizzazione», Diritto Marittimo, 2, págs. 374-398. Por otra parte, la doctrina también ha señalado la necesidad, siempre que las Autoridades Portuarias desempeńen actividades económicas, de establecer una clara separación entre la actividad de administración y la actividad de empresa, tanto desde el punto de vista organizativo y de gestión como contable, con el fin de evitar que la Autoridad Portuaria Administración acabe subvencionado a la Autoridad Portuaria empresa, con la consiguiente distorsión de la competencia intraportuaria. 
La Ley de 1994 no contiene ningún pronunciamiento explícito al respecto, limitándose a señalar que las Autoridades Portuarias tienen personalidad jurídica de derecho público. No obstante, a partir de la entrada en vigor de la Ley, tanto la doctrina como la jurisprudencia se inclinaron mayoritariamente por reconocer a aquellas la condición de entes públicos económicos ${ }^{42}$, algo que, paradójicamente, parecía alejarlas del modelo de Landlord port supuestamente pretendido por la norma para acercarlas al modelo distinto de Operating port. El origen de este posicionamiento se encuentra en la situación de las antiguas Organizaciones Portuarias, cuyas actividades eminentemente empresariales hicieron que la doctrina y la jurisprudencia sí se mostraran prácticamente unánimes a la hora de calificarlas como entes públicos económicos. A partir de aquí, y tras la entrada en vigor de la Ley, una y otra han puesto de manifiesto la subsistencia en la regulación legal de algunos elementos que parecerían revelar una voluntad del legislador de «continuar» en la situación anterior, atribuyendo así a los entes gestores del sector portuario caracteres propios de los entes públicos económicos. En este sentido, se ha destacado que la institución de las nuevas Autoridades Portuarias se realiza sobre la base de factores puramente comerciales (volumen de tráfico); es más, la propia clasificación de los puertos responde a un criterio de relevancia económica (internacional, nacional o regional). Y todo esto, además, sin olvidar las facultades que los artículos 6.6 y 23.5, ya comentados anteriormente, ofrecen a las Autoridades Portuarias para intervenir en el desarrollo de actividades de orden netamente económico ${ }^{43}$.

Con todo, como ya habíamos advertido, la cuestión no resulta pacífica. Y así, a la posición de quienes ponen el énfasis en las actividades de naturaleza comercial que desarrollan las Autoridades Portuarias cabe oponer la de aquellos otros que se esfuerzan en destacar cómo la Ley de 1994 atribuye a los entes portuarios una función preeminentemente reguladora, de dirección,

42 Sobre la noción de ente público económico puede verse, entre otros, D. Sorace (2007), Diritto delle amministrazioni publiche, Bolonia: Il Mulino (págs. 242-248).

43 Estos argumentos han sido principalmente los que han llevado a un sector importante de la jurisprudencia a reconocer la presencia en las Autoridades Portuarias de una fuerte connotación económica, más allá de las funciones de disciplina y coordinación del sector. En esta línea, el Consejo de Estado, en su resolución de 5 de julio de 2008, ha afirmado que los intereses públicos confiados a las Autoridades Portuarias serían aquellos propiamente económicos y no sociales, como el de asegurar e incrementar el correcto, ordenado y eficiente desarrollo del comercio marítimo sin gravar más las finanzas públicas, esto es, dentro de un marco de gestión tendencialmente autosuficiente fundado — como se ha dicho para los entes públicos económicos - sobre el producto de la actividad del ente. 
coordinación, programación y control de la actividad productiva desarrollada por los sujetos privados ${ }^{44}$.

La Ley 296/2006, de 27 de diciembre (ley financiera para el año 2007), trató de resolver el debate que se había suscitado en torno a la aplicación o no del IVA a los cánones demaniales percibidos por las Autoridades Portuarias ${ }^{45}$, y a tal efecto estableció (art. 1) que dichos cánones no constituían contraprestaciones sujetas a la imposición del IVA, por razón precisamente de la naturaleza jurídica de aquellas como entes públicos no económicos. Al margen de la relevancia de la cuestión estrictamente tributaria, la disposición legal suponía el primer pronunciamiento expreso del legislador sobre la naturaleza jurídica de las Autoridades Portuarias, lo que hizo que la jurisprudencia viera en la previsión de la Ley una suerte de «interpretación auténtica» sobre la naturaleza jurídica de los entes portuarios. Y así, llegara a la conclusión de que tales entes debían reconducirse al ámbito subjetivo de la categoría de «administración pública» previsto en el Decreto Legislativo 165/2001, de 30 de marzo, relativo a las normas generales sobre la regulación del trabajo en las dependencias de las administraciones públicas ${ }^{46}$. Tal planteamiento, sin embargo, ha sido objeto de crítica por un sector destacado de la doctrina, que ha rechazado que lo dicho por la Ley de 2006, habida cuenta su naturaleza y finalidad, pueda ser entendido como una afirmación concluyente de la condición de los entes portuarios como entes públicos no económicos ${ }^{47}$.

44 En este sentido, véase F. Nunziata (1995), «Natura giuridica dell'autorità portuale», Studi Marittimi, págs. 25-26.

45 En su Sentencia de 25 de julio de 2005, la Corte de Casación había señalado que la gestión de los bienes demaniales por parte de las Autoridades Portuarias tenía un carácter esencialmente comercial. Y de ahí había llegado a la afirmación de que la percepción de los cánones demaniales, no obstante la ausencia evidente de finalidad lucrativa, constituía una operación de tipo comercial sujeta al gravamen del IVA. Tal parecer, sin embargo, fue posteriormente contradicho por el Consejo de Estado (9 de julio de 2002), que calificó la gestión de los bienes demaniales como «ejercicio de funciones estatales», excluyendo por tanto la aplicación del IVA.

46 Dicho precepto establece la definición de "administración pública», señalando que en esta categoría deben comprenderse, entre muchos otros sujetos, «todos los entes públicos no económicos nacionales, regionales y locales».

47 M. Calabro (2011: 2943-2946), ha señalado que la Ley financiera no está legitimada para contener normas de carácter organizativo, quedando limitada al establecimiento de normas con finalidades u objetivos exclusivamente financieros. En este sentido, el mismo autor ha indicado que la expresión utilizada por la Ley de 2006, al referirse a la condición de las Autoridades Portuarias, debe entenderse como una afirmación de carácter puramente instrumental, cuyo objetivo no es otro que el de tratar de justificar la exclusión del IVA de los cánones concesionales. 
En definitiva, sea cual sea la posición que se defienda, en ambos casos no queda más remedio que reconocer, por un lado, que el núcleo principal de las funciones que la Ley de 1994 atribuye a las Autoridades Portuarias tienen un marcado carácter público ${ }^{48}$, pero por otro lado, que el ejercicio de esas funciones concurre con el reconocimiento a los entes portuarios de un amplio margen de intervención empresarial. Así las cosas, no parece que la Ley 84/1994 haya sabido resolver adecuadamente el objetivo pretendido de separar de forma nítida la actividad reguladora de la actividad empresarial ${ }^{49}$. Las amplias facultades atribuidas por el legislador a las Autoridades Portuarias para el ejercicio de actividades económicas o empresariales dificulta de manera cierta que se pueda llegar a una conclusión definitiva en relación a su naturaleza jurídica. Y eso, a la postre, provoca una situación de incertidumbre que, más allá de la problemática que pueda suscitarse en el ámbito puramente fiscal ${ }^{50}$, pone en riesgo la efectiva realización del proceso de liberalización de las operaciones y servicios en el ámbito portuario.

\section{LA PROPUESTA DE REFORMA DE LA LEGISLACIÓN PORTUARIA}

\section{DEFICIENCIAS Y RETOS DEL SISTEMA PORTUARIO}

Después de más de veinte años de vigencia, el régimen de administración y explotación de los puertos italianos evidencia algunos puntos críticos

48 Sobre la naturaleza jurídica de las Autoridades Portuarias y la preferencia por su configuración como entes públicos no económicos puede verse M. R. Sapasiano (2007), «Spunti di riflessione in ordine alla natura giuridica e all'autonomia dell'autorità portuale», Foro Amministrativo-TAR, 9, págs. 2972-2974.

49 La Autoridad de Defensa de la Competencia y del Marcado ha seńalado (16 de octubre de 1997) que las Autoridades Portuarias, vía su presencia activa en las sociedades encargadas de la prestación de servicios de interés general, adquieren la condición de empresa; pero a la vez, por otro lado, su poder regulador en materia de acceso al mercado y de desarrollo de los servicios hace que dichas Autoridades Portuarias ostenten una posición dominante, de privilegio.

50 Paradójicamente, la Agencia Tributaria, en su resolución 32/E, de 26 de abril de 2010 , ha dispuesto, no obstante la previsión establecida por la Ley 296/2006, la aplicación del régimen del IVA al otorgamiento de una concesión mediante la cual la Autoridad Portuaria confiaba a una entidad privada el servicio de estación marítima, señalándose — según el parecer de la Agencia - que en este caso particular el ente portuario no actuaría en su vertiente de pública autoridad, sino de la misma manera que un operador económico privado. 
que han afectado negativamente a la competitividad de estos respecto a otros puertos del Mediterráneo ${ }^{51}$. El contexto en el que hoy en día operan las Autoridades Portuarias ha cambiado significativamente en relación al que había antes de la aparición de estas, o incluso en el momento de aprobarse la Ley de 1994. Los puertos no se entienden ya como un simple conjunto de bienes demaniales idóneos para constituir el abrigo de las embarcaciones y garantizar la seguridad de la navegación (concepción estática, de perfil netamente público), sino que representan una realidad compleja, integrada en la red global de transportes, cuyos elementos están funcionalmente orientados a un fin esencial, el de canalizar y promover el tráfico comercial ${ }^{52}$ mediante la prestación eficiente de servicios destinados al pasaje y al movimiento e intercambio modal de las mercancías (concepción dinámica, de perfil marcadamente empresarial $)^{53}$. Así pues, en este cambio de escenario, la intervención pública en los puertos difícilmente se puede justificar por la necesidad de realizar y prestar directamente las operaciones y servicios portuarios, es decir, desde una posición de operador interno en el mercado, sino que debe responder a un rol mucho más neutral y externo. Dicho de otra manera, la responsabilidad básica de las Autoridades Portuarias ha de ser sobre todo la de organizar el uso del demanio portuario conforme a las exigencias de la explotación portuaria, garantizando a la vez la eficiencia y accesibilidad (competencia intraportuaria) al mercado de las operaciones y servicios que se desarrolla sobre el mencionado dominio público. Y todo ello, en último término, de forma tal que se consiga conciliar la satisfacción de los intereses de los usuarios finales del puerto, promoviendo así la competencia interportuaria, con la realización de los intereses públicos conexos a la gestión del puerto. Desde este punto de vista, en fin, es fácil imaginar que la configuración de los entes portuarios debe estar preferentemente orientada hacia una concepción de los mismos como auténticos administradores autónomos e imparciales de los bienes y las actividades vinculadas a la explotación portuaria. Eso precisamente es lo que pretendió la Ley de 1994, como ya sabemos. Sin embargo, sabemos también que su intento

51 E. Musso y C. Ferrari (2009: 992-998) aportan algunos datos que revelan la pérdida de competitividad de los puertos italianos; como significativo, puede señalarse el siguiente: la cuota de mercado de los puertos italianos respecto al tráfico de contenedores descendió, entre los ańos 2003 a 2008, del 20,7\% al 15,7\%.

52 Desde este punto de vista, uno de los principales retos que afrontan los puertos italianos es el de la captación de los tráficos emergentes, procedentes de la zona asiática (China, Japón, India), teniendo en cuenta que en los últimos años los puertos del norte de Europa, y también los españoles, han crecido más rápido que los italianos.

53 M. Calabró (2011: 2953-2958). En la misma línea, véase F. Manganaro (2008), «Il porto, da "bene demaniale" ad "azienda” ", Il Diritto dell'economia, 2, págs. 257-275. 
no alcanzó los resultados supuestamente deseados. La confusa relación entre funciones públicas y empresariales constituye un importante hándicap que ha acabado entorpeciendo la competitividad de los puertos italianos.

Junto con lo que se acaba de decir, otro de los problemas relevantes que afectan a la eficiencia del sistema portuario — según ha señalado la doctrinaes el de la existencia de un número excesivo de puertos de primer orden y de Autoridades Portuarias, que provoca una notable dispersión de los recursos públicos y que pone en serias dificultades la realización de un modelo de excelencia ${ }^{54}$. A eso hay que sumar, además, la ausencia de mecanismos o instrumentos de coordinación entre los puertos que actúan en un mismo rango geográfico, que imposibilita así la aplicación de economías de escala. Y a todo eso hay que añadir también, finalmente, la falta de una efectiva autonomía financiera de las Autoridades Portuarias, que impide que se pueda establecer una correcta vinculación entre el balance de costes y beneficios y las estrategias comerciales diseñadas por cada puerto. $\mathrm{Al}$ respecto de esto último hay que advertir que, más allá de la proclamación legal de la autonomía financiera de las Autoridades Portuarias, lo cierto es que los ingresos de estas dependen básicamente de los cánones por concesiones y por la autorización de las operaciones y servicios portuarios, en tanto que la mayor parte de los rendimientos generados por el tráfico portuario (por ejemplo, IVA de las mercancías embarcadas y desembarcadas) queda en manos del Estado. Eso significa, pues, que los ingresos percibidos directamente por las Autoridades Portuarias representan un porcentaje muy reducido del flujo económico generado por el tráfico portuario. O lo que es lo mismo, que la mayor parte de los rendimientos económicos están centralizados. Y aunque dichos rendimientos son objeto posteriormente de redistribución desde el Estado, la verdad es que con este sistema la operatividad de las Autoridades Portuarias acaba dependiendo de unas decisiones "políticas", adoptadas desde el poder central, que con frecuencia no responden a lógicas de economicidad y eficiencia de la explotación del correspondiente puerto ${ }^{55}$.

54 E. Musso y C. Ferrari (2009: 992-998) han señalado que se trata de un error de estrategia. Según los autores, en un mundo del transporte dominado por grandes operadores mundiales, resulta anacrónico y poco efectivo pretender que el flujo logístico desde/hacia Italia se deba articular a través de decenas de puertos en lugar de concentrar dicho flujo en unos pocos nodos estratégicos. La proliferación de Autoridades Portuarias no hace otra cosa que fomentar la aparición de lógicas «parroquiales», es decir, de ámbito restringido, que no tienen en cuenta las ventajas de las sinergias y las economías de escala.

55 La tradicional situación de insuficiencia económica de las Autoridades Portuarias, que obligaba a que fueran el Estado o las regiones las que tuvieran que encargarse de las 
En definitiva, todos esos son los principales obstáculos a los que se enfrentan los puertos italianos y que lastran su posición competitiva. El gran reto que se presenta, pues, es el de abordar una reforma del régimen de administración portuaria que haga realidad el objetivo de convertir a las Autoridades Portuarias en verdaderos sujetos reguladores que, dotados de suficiente autonomía financiera, tengan capacidad efectiva para gestionar los bienes y actividades del puerto conforme a estrategias de promoción de la competitividad portuaria en el mercado de las redes del transporte intermodal.

\section{EL PROYECTO DE MODIFICACIÓN DE LA LEY 84/1994}

Desde hace algunos años se discute en el Parlamento una propuesta de modificación de la Ley de $1994^{56}$ que está orientada, en líneas generales, a afrontar ese reto al que antes hemos hecho referencia. O sea, un texto de reforma de la legislación portuaria destinado a dotar a las Autoridades Portuarias de los instrumentos jurídicos y económicos necesarios que les permitan gobernar con mayor autonomía y responsabilidad los diferentes

actuaciones más importantes para la explotación del puerto (construcción de muelles, dragados, etc.), trató de ser paliada por la Ley 296/2006, de 27 de diciembre, atribuyendo a los entes portuarios determinados rendimientos vinculados a la actividad portuaria (las llamadas tasas de anclaje y sobre las mercancías embarcadas y desembarcadas). Sin embargo, la solución no resultó nada exitosa, pues lo que hicieron las Autoridades Portuarias, para poder hacer frente a la competencia de otros puertos del Mediterráneo, fue reducir prácticamente a cero la percepción de aquellos rendimientos. La fórmula actual fue introducida algunos años más tarde por el Decreto 83/2012, de 22 de junio (luego convertido en Ley 134/2010, de 7 de agosto), cuyo artículo 14 incorporó a la Ley de 1994 un nuevo artículo, el 18 bis (posteriormente modificado por la Ley 98/2013, de 9 de agosto), en el que se prevé la creación de un fondo para la financiación de las inversiones de adecuación de los puertos. Dicho fondo se nutre con el $1 \%$ del IVA de las mercancías introducidas en Italia a través de cada uno de los puertos. Y luego es distribuido por el Ministerio, atribuyendo a cada puerto el $80 \%$ del IVA de las mercancías introducidas por el propio puerto (con esto se quiere potenciar la competitividad y eficiencia del puerto), y distribuyendo el $20 \%$ restante entre los puertos más «débiles» desde el punto de vista comercial (con esto se quiere establecer un mecanismo de equilibrio entre los diferentes puertos). Como se puede comprobar, el sistema descansa sobre un fondo único estatal. O lo que es lo mismo, el sistema no permite a las Autoridades Portuarias la percepción y gestión de una parte de los ingresos obtenidos por cada una de ellas.

56 En realidad los textos presentados durante los últimos años han sido varios. Finalmente, el Comité constituido en el seno de la VIII Comisión del Senado ha elaborado un texto unificado (presentado el 3 de abril de 2013) de las diferentes propuestas. 
puertos encomendados a su gestión, todo eso con el objetivo último de reforzar la posición competitiva de los puertos italianos en el contexto del tráfico comercial internacional ${ }^{57}$.

Como premisa para alcanzar el objetivo perseguido, el proyecto de modificación de la Ley de 1994 se mantiene firme - según se dice en la exposición de motivos- en el principio esencial de distinción entre funciones de programación y control, asignadas a las Autoridades Portuarias, y desarrollo de actividades económicas, dejadas en manos de la iniciativa privada empresarial. A partir de ahí, la reforma del régimen de administración y explotación portuaria avanza sobre tres grandes ejes: i) establecer la regulación de las concesiones y autorizaciones portuarias; ii) intervenir sobre las fuentes de financiación de las Autoridades Portuarias; y iii) redefinir las funciones y régimen de organización de los mencionados entes portuarios.

Cabe advertir, no obstante, que las anteriores líneas de acción no son las únicas que aborda el proyecto de reforma, sino que a esas se añaden otras que, aunque no están tan estrechamente relacionadas con el objetivo de promover la competitividad del sistema portuario, no por eso dejan de ser relevantes ${ }^{58}$. $Y$ una en especial, que no podemos omitir aquí, la que se concreta en la redefinición del reparto competencial en materia de puertos entre el Estado y las regiones como consecuencia de la modificación —operada por la Ley 3/2001, de 18 de octubre- del título V de la Constitución. Desde hace tiempo las regiones italianas venían reivindicando un mayor protagonismo en el gobierno de los puertos, pero sus aspiraciones fueron desatendidas por la Ley de 1994,

57 La justificación de la propuesta presentada al Senado hace especial hincapié en la importancia de la reforma no solo desde el punto de vista de la valorización del sistema portuario, sino también de la economía italiana en general. De lo que se trata es de situar a los puertos italianos en una posición relevante en el escenario internacional del tráfico marítimo comercial, aprovechando el papel estratégico que tiene el Mediterráneo en ese tráfico como consecuencia del protagonismo creciente de la economía asiática y de la no finalización de las obras de ampliación del canal de Panamá.

Por un lado, se modifica la regulación de la planificación portuaria, del llamado Plan Regulador del Puerto, que es el instrumento encargado de delimitar el área portuaria y determinar las características y destino funcional de las diferentes zonas comprendidas dentro del ámbito portuario. La modificación propuesta va en la línea de tratar de simplificar y agilizar la tramitación de la planificación portuaria. Y por otro lado, se ha de destacar el intento del legislador por clarificar, en mayor medida que lo que lo ha hecho la Ley de 1994, la distribución de responsabilidades entre las Autoridades Portuarias y las marítimas. En cualquier caso, el criterio básico de distinción sigue siendo el mismo que el contenido en el texto originario de la Ley de 1994 (véase al respecto de este punto lo dicho en el apartado II.1). 
de marcado corte centralista ${ }^{59}$. Tras la reforma constitucional, sin embargo, los poderes e instrumentos de intervención de las regiones sobre el territorio local se han visto incrementados, con consecuencias directas sobre la materia portuaria, ya que ahora el artículo 117 de la Constitución define expresamente los puertos como un ámbito de competencias concurrentes del Estado y de las regiones ${ }^{60}$. Por esa razón, pues, la propuesta de reforma de la Ley de 1994 se ha visto en la obligación de intervenir también sobre la posición del Estado y de las regiones en la gestión de los puertos, algo que pretende llevar a cabo por la vía de establecer una nueva clasificación de los mismos. En realidad, más que de una nueva clasificación de lo que se trata es de reordenar las clases de puertos ya contempladas en la Ley de $1994^{61}$, conforme a las siguientes nuevas categorías: i) categoría I, o puertos destinados a la defensa militar o a la seguridad del Estado; ii) categoría II, reservada a los puertos de relevancia económica nacional o internacional, esto es, a aquellos puertos que por razón de la tipología del tráfico, de su ubicación y de su conexión con las grandes redes de transporte europeas y transeuropeas constituyen nodos esenciales de intercambio modal en la trama del comercio internacional; y iii) categoría III, o resto de puertos, es decir, los puertos de relevancia económica regional o interregional. Dejando al margen la primera categoría, cuya Administración se reserva en exclusiva al Estado por razones obvias, el proyecto de reforma deja en manos de las Autoridades Portuarias la gestión de los puertos de categoría

59 M. Bennici (2006), «La governance dei porti italiani: la Legge 84/1994 e le sue proposte di reforma", Istituzini del federalismo, Rivista di Studi giuridici e Politici, 1, págs. 121-122.

60 Sobre el tema puede verse, entre otros, G. de Vergottini (2001), «Le competenze in materia di porti alla luce della reforma della Costittuzione», Diritto Amministrativo, 4, págs. 593-612. Como ha explicado la doctrina, con la reforma constitucional de 2001 los puertos han quedado indudablemente comprendidos entre las materias de competencia normativa concurrente entre el Estado y las regiones, lo que significa que corresponde al primero — al margen de la competencia que ostenta sobre otras materias que pueden interseccionar con los puertos - la fijación de los principios fundamentales que disciplinan la materia, en tanto que corresponde a las segundas el ejercicio de la potestad reglamentaria. Así las cosas, un destacado sector de la doctrina no ha dudado en afirmar que tras la reforma de 2001 debe reconocerse a las regiones una sobrevenida competencia normativa para la ejecución de la Ley 84/1994 [véase, entre otros, L. Cuocolo (2009), «Il rilievo strategico dei porti tra diritto e economía», Quaderni Regionali, 3, págs. 926-927].

61 La clasificación actual de los puertos establecida por la Ley de 1994 aparece reseñada ut supra, en la nota 19. 
$\mathrm{II}^{62}$, y en cambio atribuye a las regiones la reglamentación y administración de los puertos de categoría III, siempre respetando, claro está, los principios fundamentales establecidos por la legislación estatal.

Por lo que se refiere en particular a los puertos de categoría II, que son al fin y al cabo los de mayor relevancia económica, cuya gestión se encomienda a las Autoridades Portuarias, ya dijimos antes cuáles son las líneas esenciales sobre las que se mueve la propuesta de reforma, con el objetivo, que también dijimos, de reforzar la autonomía de aquellas y su protagonismo en la explotación del servicio de puertos.

Comenzando por el acceso al mercado de las operaciones y servicios portuarios, o mejor dicho, por los títulos que habilitan para dicho acceso, hay que decir que la propuesta de reforma mantiene la distinción actual de la Ley de 1994 entre "autorización», para el ejercicio de operaciones y servicios portuarios, y «concesión», para la ocupación de las áreas de dominio público necesarias para la realización y prestación de las mencionadas operaciones y servicios. Asimismo, igual que en la regulación actual, se admite que ambos títulos puedan actuar de manera independiente, es decir, que existan empresas que operen en el puerto, prestando servicios, sin disponer de una estructura fija -muelles o terminales - concesionada. O bien que suceda todo lo contrario, esto es, que la concesión se otorgue precisamente a las empresas autorizadas para la prestación de operaciones y servicios portuarios ${ }^{63}$. En relación a las concesiones, es sin duda aquí donde se prevén las mayores novedades,

62 El proyecto de reforma contiene una enumeración de los puertos administrados por las Autoridades Portuarias, que coincide - a excepción de Manfredonia - con la resultante de la Ley de 1994 y las adiciones producidas posteriormente (véase ut supra nota 17). Por otra parte, se prevé que esa relación pueda variar al alza, es decir, se puedan constituir nuevas Autoridades, cuando los niveles medios de tráfico anual registrado en el correspondiente puerto durante el último quinquenio superen alguno de los siguientes límites: 3 millones de toneladas de mercancías sólidas; 2 millones de toneladas de graneles líquidos; 300000 TEU (twenty feet equivalent unit): o 1 millón de pasajeros, excluido el tráfico local. Por el contrario, podrá suprimirse la Autoridad Portuaria, aplicándose entonces la normativa correspondiente a los puertos de categoría III, cuando los niveles medios de trafico, computados durante el mismo periodo de cinco ańos, no superen ninguno de los límites seńalados antes.

63 La propuesta de reforma mantiene la remisión que el artículo 18.1 efectúa al artículo 16.3, y que ha dado lugar a la crítica de un sector de la doctrina al entender que la relación entre ambos títulos no queda adecuadamente resuelta desde el punto de vista procedimental (véase lo dicho ut supra en la nota 33). En atención al texto del nuevo artículo 18, cabe entender que el otorgamiento de la autorización y el otorgamiento de la concesión siguen manteniendo procedimientos separados, al contrario de lo que 
que se concretan en un aumento considerable de los poderes de intervención de las Autoridades Portuarias. Según sabemos ${ }^{64}$, la legislación vigente reserva a la Administración central, a través del Ministerio competente, la adopción de importantes decisiones que afectan al régimen de las concesiones, como son las referidas al establecimiento de su duración, la determinación de los poderes de vigilancia y control de la Autoridad concedente, la forma de renovación de las concesiones o la determinación de los límites mínimos del canon que deben satisfacer los concesionarios, así como también la relativa a la fijación de los criterios que deben seguir las Autoridades concedentes a fin de que en el ámbito portuario se reserve espacio operativo suficiente para el desarrollo de operaciones portuarias por parte de empresas que no sean titulares de concesión. Pues bien, con la reforma en trámite de la Ley de 1994 todas esas responsabilidades — junto con el propio otorgamiento del título concesional_ quedan en manos de las Autoridades Portuarias, de tal manera que su capacidad de gestión del dominio público portuario resulta notablemente incrementada ${ }^{65}$. Y con eso, por consiguiente, su capacidad de vincular dicha gestión al desarrollo de las estrategias comerciales y de fomento de la competitividad del puerto correspondiente.

Por otro lado, en segundo lugar, el proyecto de reforma trata de reforzar la suficiencia financiera de las Autoridades Portuarias, especialmente para la realización de inversiones destinadas a la conexión del puerto con las redes de transporte viarias y ferroviarias. En realidad, sin embargo, la modificación de la Ley de 1994 no parece que vaya a mejorar significativamente la pobre realidad económica de los entes portuarios: sus ingresos directos —cánones por autorizaciones y concesiones, tasa de anclaje y tasa de las mercancías embarcadas y desembarcadas - siguen representando un porcentaje muy reducido del flujo económico generado por el tráfico portuario; y su financiación sigue dependiendo en gran medida de las decisiones adoptadas desde el poder central. Así, junto al fondo de inversiones que establece el artículo 18 bis de la Ley de $1994^{66}$, la propuesta de reforma prevé la instauración de otro fondo dirigido específicamente a la financiación de las inversiones relativas a la conexión del

ha propugnado parte de la doctrina, que considera conveniente que el otorgamiento de ambos títulos se hubiera unificado en un único procedimiento.

Al establecer la enumeración de las funciones que son asignadas a las Autoridades Portuarias (art. 6), la propuesta de reforma incorpora una importante novedad respecto a las previsiones actuales de la Ley de 1994: la que se concreta en atribuir a dichos entes portuarios «la administración en exclusiva de las áreas y de los bienes del demanio marítimo comprendidos en la propia circunscripción». 
puerto con las redes de transporte, viarias y ferroviarias. Sin embargo, resulta que dicho fondo - que se nutre con la aportación estatal equivalente al 5\% de los recursos destinados a inversiones de las entidades gestoras de las redes ferroviaria (Rete Ferroviaria Italiana: RFI, S.p.A.) y viaria (Azienda Nazionale Autonoma delle Strade: ANAS, S.p.A.) — ha de depender del Ministerio de las Infraestructuras y los Transportes, a quien corresponderá también determinar, mediante Decreto, las modalidades y criterios de su reparto. En resumidas cuentas, como ya habíamos dicho, la operatividad de las Autoridades Portuarias continúa dependiendo en su mayor parte de decisiones y estrategias diseñadas desde el poder central, alejadas por tanto en muchas ocasiones de las necesidades y tácticas competitivas de los correspondientes puertos.

Finalmente, en tercer lugar, el proyecto de reforma incide sobre el régimen de organización y funciones de las Autoridades Portuarias. En cuanto a lo primero, la reforma parece avanzar hacia un sistema presidencialista de gobierno de los entes portuarios, reforzando la figura y atribuciones del presidente. Y a la vez, junto con eso, pretende atribuir mayor protagonismo a las regiones en la designación de aquel ${ }^{67}$. Lo cierto, sin embargo, es que la propuesta de reforma no elimina la fuerte dependencia que las Autoridades Portuarias mantienen respecto del Ministerio, o sea, respecto del poder central, algo que se hace especialmente manifiesto en lo que se refiere al régimen de control sobre la gestión patrimonial y financiera de los entes portuarios ${ }^{68}$. En cuanto a lo segundo, esto es, las funciones de

67 La propuesta de reforma amplía el mandato del presidente de 4 a 5 años. Asimismo, modifica el sistema de determinación de las atribuciones del presidente: frente al sistema de lista que contempla actualmente la Ley de 1994, la reforma establece una definición de las atribuciones de aquel mucho más genérica, de la que resulta una suerte de competencia residual, en la medida que han de corresponder al presidente todos los poderes de administración ordinaria y extraordinaria no conferidos por la Ley a otros órganos. Por último, el nombramiento del presidente se mantiene en manos del Ministerio, pero ya no sobre la base de una terna propuesta respectivamente por la Región, los Ayuntamientos y las Cámaras de Comercio, Industria, Artesanía y Agricultura comprendidos en la correspondiente circunscripción, sino en atención al candidato directamente designado por el presidente de la Junta Regional (con el acuerdo entre región, ayuntamientos y Cámaras de Comercio, Industria, Artesanía y Agricultura).

68 En este sentido, el proyecto de modificación prevé, en términos idénticos a los de la Ley de 1994, que las Autoridades Portuarias están sometidas al control del Ministerio de las Infraestructuras y los Transportes, al cual corresponde presentar al Parlamento, cada año, una relación general sobre las actividades de los entes portuarios. Asimismo, la reforma prevé expresamente, de modo semejante a la regulación actual, que las 
las Autoridades Portuarias, el proyecto de reforma proclama los principios fundamentales de la disciplina portuaria, y entre ellos aquel que propugna la asignación a los entes portuarios de responsabilidades de carácter eminentemente público, concretadas en las tradicionales funciones de dirección, programación, coordinación, regulación, promoción y control de las operaciones portuarias y de las demás actividades, comerciales e industriales, ejercitadas en el puerto. Desde este punto de vista, la propuesta de reforma se mantiene firme en el propósito, que ya perseguía la Ley de 1994, de reconducir la actividad de las Autoridades Portuarias hacia el ámbito estrictamente administrativo, alejándolas del ejercicio de las actividades económicas. En este sentido, más aún, la propuesta de reforma se pronuncia expresamente sobre la naturaleza jurídica de las Autoridades Portuarias, calificándolas de manera decidida como «entes públicos no económicos» de relevancia nacional y sujetos a una regulación específica. Como decíamos, parece que existe una clara toma de posición por parte del legislador portuario en la línea de separar nítidamente la actividad administrativa y la actividad económica, queriendo encuadrar a las Autoridades Portuarias dentro del ámbito de las «administraciones públicas». Sin embargo, más allá de la expresa calificación legal, la verdad es que el proyecto de reforma legal no acaba de eliminar todos aquellos aspectos de la regulación actual que han provocado la discusión sobre la naturaleza jurídica de los entes portuarios. Algunas de las contradicciones que han sido denunciadas por la doctrina, y que ya hemos puesto de manifiesto anteriormente, sobre todo la que supone reconocer a las Autoridades Portuarias la facultad de prestar todos o algunos de los servicios de interés general, subsisten en la propuesta de reforma ${ }^{69}$. Desde este punto de vista, bien podría decirse que la propuesta de reforma de la Ley de 1994 sigue sin ser del todo coherente con la voluntad expresada por dicho texto legal de liberalizar completamente el sector de las operaciones y servicios portuarios. Como mínimo, la reforma en trámite debería dejar sentado, sin posibilidad de suscitar ninguna duda, que la realización de actividades empresariales por parte de las Autoridades Portuarias solo podrá admitirse en supuestos de ausencia de mercado.

decisiones relativas al presupuesto del ente portuario deben someterse a la aprobación del mencionado Ministerio de las Infraestructuras y los Transportes.

69

La propuesta de reforma deja intacta la redacción del artículo 23.5 de la Ley de 1994.

En cambio, sí que elimina del artículo 6.6 la alusión a la posibilidad de que las Autoridades Portuarias puedan constituir o participar sociedades que ejerzan actividades accesorias o instrumentales respecto a las funciones institucionales confiadas a tales entes portuarios. 
En definitiva, como ha señalado la doctrina ${ }^{70}$, la reforma podía haber seguido dos opciones: o bien confirmar y reforzar la posición de las Autoridades Portuarias como auténticas administraciones públicas, dotadas además de verdadera autonomía, o bien optar por la solución totalmente opuesta, esto es, convertir a las Autoridades Portuarias en sociedades de capital con vocación de desarrollar actividades empresariales ${ }^{71}$. Sin embargo, a la vista del tenor literal que presenta actualmente el proyecto de reforma, parece que el legislador vaya a quedarse en una situación intermedia. $\mathrm{O}$ por decirlo de otra manera, parece que efectivamente se pretende reforzar la vertiente pública de las Autoridades Portuarias, pero que no se tiene el coraje o la decisión suficiente para afrontar todas las consecuencias vinculadas a ese planteamiento.

70 M. Calabró (2011: 2953-2958).

71 Este sería el modelo de los puertos ingleses, o de algunos otros puertos de la Europa continental como el de Rotterdam, en Holanda, Hamburgo, en Alemania, o Pireo, en Grecia. 
